\title{
Escrever, incorporar, inscrever-se: práticas de criação de si na formação teatral
}

\author{
Writing, embodying, inscribing oneself: \\ practices of creation of the self in theater education \\ Escribir, incorporar, escribir a sí mismo: \\ prácticas de creación de sí mismo en la formación teatral
}

\author{
Celina Nunes De AlcÂNTARA* \\ GILBERTO ICLE**
}

\begin{abstract}
RESUMO - Este texto apresenta uma discussão sobre o estatuto e a importância da escrita na formação teatral, considerando o ambiente universitário da formação em teatro. Para tanto, discorre sobre as práticas corporais, aludindo aos conceitos de criação, ficção, criação de si e escrita de si na tentativa de aduzir a uma noção de escrita para além do mero registro instrumental das práticas artísticas. O texto propõe a escrita como instrumento de formação do sujeito, enfatizando as práticas de si como elementos por intermédio dos quais a atividade artística transbordaria para a vida. Problematiza-se, portanto, a escrita inserida no processo de criação como modo de tornar-se sujeito de uma determinada ética.
\end{abstract}

Palavras-chave - Formação. Teatro. Escrita. Práticas de si. Michel Foucault.

\begin{abstract}
This paper discusses the status and importance of writing in theatre education, considering the environment of a theatre undergraduate programme. To this end, it deals with physical practices, alluding to concepts of creation, fiction, self creation, and writing about oneself in an attempt to bring forward a notion of writing beyond the mere instrumental record of artistic practices. The text proposes writing as an instrument to educate the individual, emphasizing the practices of the self as elements through which artistic activity would overflow into life. Therefore, it discusses writing as part of the creative process as a way to become an individual following a particular ethics.

Keywords - Education. Theatre. Writing. Practices of the self. Michel Foucault.

RESUMEN - En este trabajo se presenta una discusión sobre el estatuto y la importancia de la escritura en la formación teatral, teniendo en cuenta el marco de la de formación universitaria en teatro. Para ello, habla de las prácticas corporales, en alusión a los conceptos de creación, de ficción, creación de sí y de escritura de sí, en un intento de aportar una idea de escribir más allá del mero registro instrumental de las prácticas artísticas. El texto propone la escritura como un instrumento de formación del sujeto, destacando las prácticas de creación como elementos a través del cual la actividad artística se desborda para la vida. Por lo tanto, problematiza la escritura adentro del proceso de creación con el fin de convertirse en objeto de una cierta ética.
\end{abstract}

Palabras clave - Formación. Teatro. Escritura. Prácticas de sí. Michel Foucault.

Este texto começa de perguntas originárias (no sentido benjaminiano de lugar do qual provem e não no sentido de início), como, por exemplo: pode o teatro transformar o sujeito em formação? E, de forma mais específica, questiona-se: pode o sujeito, durante sua formação teatral, transformar-se para além da dimensão do trabalho?
Tomamos, evidentemente, a palavra trabalho a partir de uma oposição insustentável e, assim, apenas operacional, em relação à vida. A oposição vida e trabalho, portanto, funciona tão somente como um modo por intermédio do qual podemos pensar a formação profissional para além do instrumental, podemos

\footnotetext{
*Doutora em Educação pela Universidade Federal do Rio Grande do Sul (Porto Alegre, RS, Brasil) e professora na Universidade Federal do Rio Grande do Sul (Porto Alegre, RS, Brasil). E-mail:<celinanalcantara@gmail.com>.

**Doutor em Educação pela Universidade Federal do Rio Grande do Sul (Porto Alegre, RS, Brasil) e professor na Universidade Federal do Rio Grande do Sul (Porto Alegre, RS, Brasil).E-mail: <gilbertoicle@gmail.com>.
} 
imaginar o desdobramento da formação em teatro no corpo do sujeito, no cotidiano do indivíduo, no âmago de sua vida. Nesse caminho, caberia saber se o trabalho teatral no contexto da formação superior em teatro pode, efetivamente, não apenas instrumentalizar o sujeito, não apenas ensinar-lhe a ensinar teatro, mas saber se ele, a partir disso, poderia se constituir num sujeito ético.

$\mathrm{O}$ contexto de nossa reflexão se dirige, entrementes, para os cursos de licenciatura em teatro (que formam professores de teatro para a Educação Básica), nos quais a atividade teatral se confunde com a atividade de formação pedagógica. Nossa preocupação é, com efeito, pensar a formação no contexto do ensino superior. Essa perspectiva parte de nossa experiência como formadores de professores de teatro e se dirige, retroativamente, para esse mesmo ambiente.

No contexto de nosso trabalho de formação teatral, os exercícios corporais são uma prática importante, central e que toma boa parte dos tempos e dos espaços de formação. Entretanto, há práticas complementares (serão mesmo complementares?) nas quais os alunos devem escrever sobre o processo. Esses escritos possuem diferentes modalidades: diários de bordo, cadernos de notas, relatos de processo. Outras modalidades de escrita dizem respeito a textos mais substantivos e que possuem um status muito importante no contexto da formação universitária: trabalhos de conclusão de curso e relatórios de estágio de docência.

Nos propomos a pensar, portanto, a forma segundo a qual esses escritos não apenas expressam modos de ser, mas, sobretudo, constituem os sujeitos no trajeto de suas formações. Que estatuto a escrita possui na formação teatral? Eis o foco que escolhemos para pensar a questão da formação em teatro neste artigo.

Escrever implicaria apenas um registro do processo de criação ou uma transformação do sujeito que escreve? Formar-se professor de teatro implicaria transformar-se por intermédio da própria escrita? Implicaria fazer-se eticamente ou, dito de outro modo, constituir um etos? Para desdobrar tais questões, este texto irá propor várias coisas, entre elas, o conceito de ficção de si mesmo.

Assim, neste texto, pretendemos apresentar a acepção que nos é cara, segundo a qual as práticas teatrais formativas implicam a criação de si, ao mesmo tempo em que aduzem à criação teatral. Faremos isso com o objetivo que é o cerne deste texto: pensar como a escrita está implicada nessa formação de si.

\section{PrÁticas CORPORAIS: PRÁticAS DE FICÇÃO PARA INVENTAR A SI MESMO}

No senso comum, a noção de exercícios, de práticas corporais tem sido associada a práticas mecânicas, treinamento, repetição; entretanto, nas práticas teatrais, os exercícios assumem, segundo autores como Barba (1993) ou Pezin (2012), outro estatuto. Eles plasmam no trajeto que lhes é próprio um modo de ser.

De alguma forma, eles aduzem a um modo de existir que torna os sujeitos enlaçados etopoieticamente com seus pares. Os exercícios portam e ao mesmo tempo constituem éticas específicas, comportamentos, condutas partilhadas e procedimentos artísticos.

Assim, tratar-se-ia de saber sobre o processo que engendra essa ética própria da prática teatral, essa criação de si, no sentido de um modo ético e estético de formulação de si mesmo. Vislumbraríamos, com efeito, uma relação entre formação, criação e ficção, tomando como referência uma dada prática artística - nesse caso, o campo das Artes Cênicas.

Em diferentes contextos, essas relações foram tomadas como importantes nos debates atuais, seja no campo das artes, seja no da filosofia ou da educação: indicamos, assim, o tema da "estilística da existência" (ORTEGA, 2000, p. 11). Como nos diz Nadja Hermann, esse tema, em síntese, aponta para

[...] a importância de escolher o modo de viver, quais valores orientam nosso agir, como nos constituímos, a ponto de não mais estarmos seguros para delimitar quando isto é uma questão ética ou estética, dada a interpenetração de elementos do sensível e do racional (HERMANN, 2010, p. 21).

Esse par sensível/racional referido pela autora parece remontar, justamente, a uma constituição de si na qual criação e ética se interpenetram revelando uma possibilidade de invenção de si mesmo.

Kastrup (1999) relaciona a invenção com o ato de conhecer. Para ela, o exercício da invenção é uma forma de entender o que seja conhecer. Nesse sentido, proposto pela autora, a invenção seria a própria potência que a cognição tem de diferir de si mesma. Com efeito, tal modo de conceber o que seja conhecer trouxe uma contribuição importante para esta discussão à medida que nos defrontou com a própria relação entre conhecer, constituir conhecimento e criar.

Nosso propósito, então, é o de dar a pensar sobre a criação teatral como possibilidade de "invenção de si" (KASTRUP, 1999), sobre fazer da própria existência uma experiência de constante criação, bem como de constituir a experiência de vida como modo de experienciar "atos de verdade" (FOUCAULT, 2004, p. 616), atos esses entendidos, na companhia de Foucault, como "[...] procedimentos que vinculam um sujeito a uma verdade [...]", ou, ainda, "[...] atos ritualizados em cujo decurso um certo sujeito fixa uma relação com uma certa verdade" (idem). 
As práticas corporais experimentadas no decorrer da formação superior em teatro plasmam o modo pelo qual os alunos se mostram por meio de suas práticas, de seus atos, o modo como configuram seu trabalho teatral a partir dos conhecimentos vividos no curso de graduação. Ou seja, trata-se do modo como cada um revela, por intermédio de seu trabalho ficcional, ao mesmo tempo uma forma de debruçar-se sobre si e de se constituir como persona cênica e indivíduo atuante no seu espaço de vida, nas suas relações, no seu mundo.

Isso não significa dizer que o ator está sempre representando. Não se trata de imaginar a atuação para além da dimensão do palco ou da sala de aula, mas do espraiamento de certas condutas que estão ligadas intimamente entre a disciplina corporal praticada em sala de aula e sua forma de pensar o mundo.

Seria preciso dizer, antes de tudo, que a ação do ator não consiste em fingimento, dissimulação, mas antes em um ato de recriação. Em outras palavras, trata-se da produção de uma obra ou de outra realidade - diversa da nossa cotidiana -, e nessa condição possível de ser pensada, talvez, como uma simulação, no sentido de um exercício da capacidade de tornar presente aquilo que até então não existia.

Assim, tomamos o termo ficção para falar sobre essa outra realidade - criada pelo ator no exercício de seu ofício - por entender que se trata de um trabalho de "transfiguração do real" (HERMANN, 2010, p. 40), como uma forma de operar sobre a realidade. Esse trabalho não está calcado na busca por uma verdade, tampouco por uma realidade, de modo unívoco. Ao contrário, tal processo relaciona-se com algo que movimenta e extrapola as próprias noções de verdade e realidade, já que assinala o caráter duplo da ficção - que, nesse caso, mescla, de uma maneira inseparável, o empírico e o imaginário.

Para Saer, em artigo que problematiza esse conceito, a ficção

[...] não solicita ser acreditada enquanto verdade, e sim enquanto ficção. Esse desejo não é um capricho de artista, mas a condição primeira de sua existência, porque só sendo aceita enquanto tal se compreenderá que a ficção não é a exposição romanceada de tal ou qual ideologia, mas um tratamento específico do mundo, inseparável do que trata. Este é o ponto essencial de todo o problema, e é preciso tê-lo sempre presente, caso se queira evitar a confusão de gêneros. A ficção se mantém a distância tanto dos profetas do verdadeiro quanto dos eufóricos do falso (SAER, 2009, p. 2).

A ficção teatral, assim, alude a uma dimensão extracotidiana que não é oposta à realidade. Não haveria sentido em "perguntar se o teatro é verdadeiro, se ele é real, ilusório ou mentiroso. O simples fato de formular a pergunta faz desaparecer o teatro" (FOUCAULT, 2011, p. 222).

$\mathrm{O}$ ator mergulhado no mundo da ficção trabalha na duplicidade de quem se entrega com veracidade, com profundidade, àquilo que está fazendo, porém sem perder de vista o modo de fazê-lo. Essa forma de proceder - que se refere a uma relação do ator como sua criação - constrói uma abordagem para a ficção no universo teatral, e é justamente a esse modo de operar com a ficção que aludimos quando o utilizamos como mote para problematizar as diferentes relações com a criação.

Bem, mas qual seria esse outro modo de espraiar a ficção para o prosaico da vida, de fazer da própria existência uma obra de ficção ou uma obra de arte? Ora, criar a si passa também por um processo que envolve técnicas, exercícios, um verdadeiro treino diário e exaustivo para a vida.

Entretanto, ainda que essa formação tenha muito de objetivo, de escolhas, de modos de se debruçar, de olhar, de pensar (assim como o processo de criação, que redunda numa obra de arte), existe aí um tanto de imponderado, de incerto, de móvel, de transformável, de moldável, próprio de tudo o que é vivo, ou ainda de tudo o que é da ordem da própria criação. Ao mesmo tempo, tomar o processo de criação teatral como possibilidade para pensar a criação de si mesmo talvez seja o impulso necessário para pensálo, experimentá-lo como uma prática capaz de nos fazer acessar diferentes estados, formas, camadas ficcionais que, por sua vez, seriam o elo entre experiências mais potentes de criação e a possibilidade de praticá-las no prosaico da vida.

\section{ESCREVER A SI MESMO}

Os exercícios corporais próprios da formação teatral possuem, como já dissemos, em nossa análise, uma dimensão que extrapola o simples executar mecânico de movimentos. Ao escrever, ao descrever, ao refletir sobre tais processos corporais, alunos e praticantes do teatro constituem, aparentemente, aparatos éticos: não apenas descrevem o que se faz com o corpo, mas inscrevem no corpo e com o corpo determinadas condutas.

Essa acepção de escrita encontra eco naquilo que Michel Foucault caracterizou como escrita de si. Trata-se aqui de estabelecer relações entre a escrita e o modo como os sujeitos na formação teatral se relacionam com a ideia de uma criação de si.

O termo escrita de si é analisado em $A$ hermenêutica do sujeito (FOUCAULT, 2004) e se refere a um procedimento que fazia parte da experiência ascética helenística e romana, estudada pelo filósofo francês. 
Nos escritos da Antiguidade greco-romana, a escrita era considerada um exercício físico de incorporação dos discursos e que dizia respeito "à questão da ética da palavra" (FOUCAULT, 2004, p. 427). Desse modo, a escrita configurou-se como um dos elementos do exercício de si para consigo. Mas de que maneira esse elemento se constituiu como exercício ascético para os gregos e romanos estudados por Foucault? O filósofo refere-se à escrita como um elemento do exercício sobre si, que traria a vantagem de ter dois usos possíveis e simultâneos. Para cada um, ela era usada como um procedimento pelo qual eram assimiladas as próprias coisas pensadas, e também como o meio pelo qual as coisas implantavam-se na alma, no corpo, tornando-se uma espécie de hábito ou, em todo caso, uma espécie de "virtualidade física" (FOUCAULT, 2004, p. 432).

Para o filósofo francês, o exercício de leitura como parte do procedimento ascético da escrita de si não se constituía em algo fácil, por não se tratar de uma decodificação de sinais operada com os olhos. Para se chegar a fazer um uso das palavras como convinha,

[...] era-se obrigado a pronunciá-las, pronunciá-las em voz baixa. De sorte que o exercício de ler, escrever, reler o que se tinha escrito e as anotações feitas constituía um exercício quase físico de assimilação da verdade e do logos a se reter (FOUCAULT, 2004, p. 432).

A escrita, assim pensada e formulada, parece aduzir mais uma ideia de inscrição do que puramente ao ato de escrita. Ou seja, trata-se de algo da ordem daquilo que é insculpido, gravado, entalhado no próprio ser do sujeito. Na descrição foucaultiana, por meio desse tipo de escrita, os pensamentos são guardados. Mas para que, além de guardá-los, os tenhamos à nossa disposição, é preciso colocá-los por escrito, é preciso fazer a leitura de nossos pensamentos para nós mesmos (FOUCAULT, 2004).

Escrevemos após a leitura a fim de podermos reler, reler para nós mesmos e assim incorporarmos o discurso verdadeiro que ouvimos da boca de um outro ou que lemos sob o nome de um outro. Uso para nós, mas certamente a escrita é também um uso que serve para os outros (FOUCAULT, 2004, p. 433).

As análises de Foucault indicam que o exercício ascético da escrita de si era um exercício para o coletivo, era uma prática de compartilhamento, ainda que tivesse seu lugar de acontecimento para o indivíduo, pois somente se efetivava, fazia sentido na relação com o outro. Talvez possamos vislumbrar, num exercício como esse, o modo muito concreto de compreensão e de prática de uma "tensão entre o eu singular e o nós (ethos comum)" (HERMANN, 2010, p. 20). Ou, ainda, o elemento para uma "experiência estética" que possibilitasse "ampliar nossa compreensão sobre nós mesmos e sobre o mundo, e aprimorar nossa capacidade de escolha" (HERMANN, 2010, p. 36).

O exercício da escrita como forma etopoiética de constituição de si, na medida em que envolve uma prática, também envolve um etos comum, uma necessária relação com o outro.

Isso faz lembrar uma prática comum durante a formação teatral em nível superior: a escrita do diário de trabalho. O diário de um ator ou atriz constitui uma ferramenta fundamental para pensar sobre sua formação, para que seja possível elaborar ideias em torno do próprio processo de criação, possíveis de serem compartilhadas. Nos cursos de licenciatura em teatro, o diário de ator é um instrumento comum de formação. Com efeito, a busca na elaboração de um diário como esse é mesmo a de reter o intangível, dar forma ao imponderado, entalhar o inexplicável, que diz respeito ao modo como o ator dá vida às suas ficções, como esculpe emoções em ações e as reapresenta sempre igual e sempre diferente em cada um de seus acontecimentos performáticos.

Entrementes, um ator é um sujeito da ação e suas ações deixam rastros, inscrições no seu corpo, como escritas. Tais rastros são recuperados, reestruturados, transformados a cada processo de criação, no próprio fazer, na prática de cada um, de tal forma que cada um acaba por constituir assim um vocabulário próprio, um modo de fazer, uma poética sua. O diário de ator se constitui também num elemento fundamental na elaboração dessa poética e, portanto, na criação de si, uma vez que pensar sobre a prática artística do trabalho do ator requer uma múltipla escrita ou uma escrita de si que experimente a conjunção entre ação, pensamento e escrita.

Da mesma forma, na experiência pedagógico-artística do curso de graduação aqui pensado, incentivamos os alunos-atores para que elaborassem um diário de professor. O diário de um docente pode ser, e talvez seja, instrumento importante em qualquer prática pedagógica, pois é a possibilidade de o professor (assim como já foi mencionado com relação ao ator) reportar-se a seu próprio trabalho, rememorá-lo e, por força disso, pensar sobre ele.

Ao mesmo tempo, entendemos que um diário como prática de si parece conjurar mais um efeito do "pensamento sobre o próprio sujeito" (FOUCAULT, 2004, p. 430), no sentido de uma prática que coloca em jogo os atos a partir do pensamento, e não do exemplo de um sujeito envolto com seus pensamentos. Ou seja, encerra algo que remete mais a um sentido de abrir-se para um fora de si do que fechar-se no indivíduo.

Foucault nos conta que os hypomnénata, ${ }^{1}$ no mundo grego antigo, operavam como "suportes de lembranças" (2004, p. 433). Assim, as anotações sobre as leituras ou 
sobre as conversas que tivemos ou sobre as aulas a que assistimos - objetos hoje de nossos diários -, à época dos gregos eram objetos dos hypomnénata, cujo sentido e função eram de "anotações de lembranças com que precisamente poderemos, graças à leitura ou a exercícios de memória, rememorar as coisas ditas" (FOUCAULT, 2004, p. 433).

\section{CRIADOR E OBRA: POÉTICA E ESTÉTICA DA CRIAÇÃO}

Tomar a própria existência como ato de criação seria apostar justamente naquilo que a criação tem de movimento, de inesperado, de invenção, de fecundo e, ao mesmo tempo, de escolha, de decisão, de forma. A criação, com efeito, é pensada aqui e, em alguma medida, experienciada, tanto como um modo de proceder sobre a própria existência quanto como consequência desse proceder. Tomamos, assim, a noção de procedimento no sentido da adoção de uma conduta criadora que conduz à própria vida $\mathrm{e}$, em consequência, seja constituída pela autocriação que pode emanar desse modo de experienciar a própria existência.

Ora, para tornar possível tal analogia entre o processo de criação artística e a criação da própria existência faz-se necessário, também, circunscrever ideias, tomar conceitos, explicitar referências em torno da criação artística. Partamos, então, da formulação de René Passeron (1997), segundo a qual a conduta criadora é o que conduz a atividade criadora. Essa, por sua vez implica: (1) elaboração de um objeto único (ainda que multiplicável); (2) dar existência a um pseudosujeito ${ }^{2}$ e produzir uma prática em que a obra compromete seu autor, promovendo a dupla implicação entre sujeito e objeto ou, dito de outra forma, entre obra e criador.

Para Passeron (1997), criação é conduta apresentadora que instaura a obra como presença para o outro. As ideias referidas por Passeron dizem respeito à poiésis, ou seja, ao processo de criação e tomam como referência o trabalho artístico desenvolvido no campo das Artes Visuais. As analogias com a formação teatral ficarão, entrementes, evidentes a seguir.

Para compreendermos melhor esse sentido abordado por Passeron (1997), é necessário lembrar o modo como Valéry (2007) circunscreve a origem da denominação poética e suas implicações. Para ele, houve um momento em que

[...] não se admitia que os efeitos passíveis de serem produzidos por uma obra, por mais fortes ou felizes que fossem, fossem garantia suficiente para justificar essa obra e assegurar-lhe um valor universal (VALÉRY, 2007, p. 180).
Assim,

[...] reconheceu-se muito cedo que em cada arte havia práticas a serem recomendadas, observâncias e restrições favoráveis ao maior sucesso do desígnio do artista, e que era do seu interesse conhecê-las e respeitá-las (VALÉRY, 2007, p. 180).

Criou-se com isso, "em nome da autoridade de homens muito ilustres” (VALÉRY, 2007, p. 180), certa legalização da prática artística que substituiu "as recomendações de origem empírica do início" (VALÉRY, 2007, p. 180). Ora, se por um lado regras rígidas e severas para a criação aliviaram o artista - na medida em que o isentaram de uma série de decisões delicadas, bem como de muitas responsabilidades em matéria de forma -, por outro lado, também, por vezes os excitou às invenções em direção às quais uma liberdade total nunca os levaria (VALÉRY, 2007).

Ocorre, entretanto, que a denominada "era da autoridade nas artes há muito tempo está terminada, e a palavra 'poética' só desperta agora a ideia de prescrições incômodas e antiquadas" (VALÉRY, 2007, p. 180). A partir dessas questões introdutórias, Valéry encaminha sua reflexão sobre a poética, utilizando a noção de "fazer" (2007, p. 181), a qual é sintetizada da seguinte forma: “[...] o fazer, o poiein, do qual desejo me ocupar, é aquele que termina em alguma obra e que eu acabarei restringindo, em breve, a esse gênero de obras que se convencionou chamar obras de espírito" (2007, p. 181).

A definição acima alude a duas questões importantes para a configuração da discussão feita sobre a formação teatral como criação de si e que, em ao menos num ponto, se coaduna com as ideias de Passeron (1997), apresentadas anteriormente. A saber: a primeira remete à ideia de uma conduta criadora que diz respeito ao fazer, à prática da criação, a uma poiésis; a segunda refere-se à ideia de uma produção que Valéry denomina "obra de espírito" (2007, p. 181) e define como: "aquela que o espírito quer fazer para o seu próprio uso, empregando para esse fim todos os meios físicos que possam lhe servir" (2007, p. 181).

Ao mesmo tempo, essas duas questões se amalgamam, na medida em que "uma obra de espírito só existe como ato" (VALÉRY, 2007, p. 185). Para além desse ato, restaria apenas um objeto impossível de ser conectado diretamente com o espirito que o criou, o que significa que esse ato encerra, simultaneamente, um objeto consequente de uma ação, bem como a possibilidade de relação com esse mesmo objeto, ou melhor, com a obra.

Desse modo, Valéry alude a uma relação estética com a obra de arte, que se configura como uma práxis na qual há uma dupla implicação entre sujeito e obra, assim como no processo de criação aludido por Passeron. 
Sem dúvida, a relação estética que se estabelece com uma obra de arte comporta diferentes pontos de vista e modos de se relacionar tão distintos quanto os sujeitos, os espaços, os tempos, a ordem econômica, política, a noção de valor e outros atravessamentos, implicados numa relação como essa. Mas talvez possam ser sintetizadas em duas funções opostas e constituidoras de uma obra: o produtor e o consumidor.

Conforme Valéry (2007), produtor e consumidor "são dois sistemas essencialmente separados. A obra para um é o termo (o fim); para o outro, a origem de desenvolvimentos que podem ser tão estranhos entre si quanto quisermos" (2007, p. 183). Assim, a ignorância recíproca dos pensamentos e das condições do produtor com relação ao consumidor e vice-versa é quase essencial para o efeito das obras de espírito, entendendo-as como final ou origem de certa atividade que provoca "duas ordens de modificações incomunicáveis, sendo que cada uma exige de nós uma acomodação incompatível com a outra" (2007, p. 184).

Ao se reportarem às artes e às obras, tanto Passeron quanto Valéry referem-se a algo objetável, algo a que é possível fazer referência separadamente do corpo de quem as criou. Entretanto, o exercício teatral para o qual tomamos as ideias desses dois autores é por natureza indissociável no que diz respeito a separação entre a distinção entre obra e sujeito. A performance do ator supõe sempre que obra e corpo encontrem lugar num mesmo espaço e tempo, pois as artes performativas "implicam o real através da presença de corpos vivos" (PHELAN, 1993, p. 148).

Ora, essa dupla implicação entre obra e sujeito é atávica à própria condição de possibilidade da arte teatral, ou melhor, do trabalho do ator, uma vez que a obra (teatral, performática) toma existência somente na materialidade do corpo com suas multirreferências - inclusive aquelas da linguagem teatral. Assim, conduzir um processo de vida sob a égide da criação, além de parecer algo audacioso demais, suscita muitas questões a partir das quais talvez seja possível implementar uma discussão.

Como pensar e praticar a criação na própria existência, considerando que criar, diferentemente de determinadas experiências instrumentais, por exemplo, não é um processo de constatação de evidências? Como apostar na criação não do ponto de vista de uma racionalidade instrumental que controla o processo, mas concomitantemente, considerando que evidências e racionalidade instrumental são, em alguma medida, constituintes também dos nossos atos, das nossas experiências e das nossas criações?

Por outro lado, da própria prática artística, sabe-se que a criação não é um processo espontâneo que acontece por si, mas também não é um processo voluntário, em que se tem controle de tudo o que acontece. Então, como praticá-la no próprio processo da existência, que é também permeada por essas questões? Uma ideia, portanto, que nos parece instigante é a de pensar a criação como processo de autocriação. Tratar-se-ia de refletir sobre o modo como nos tornamos aquilo que somos, o que implica pensar a criação como formulação de si, como formação, quiçá como forma de praticar a própria vida.

Nesse sentido, um caminho possível seria o de pensar o modo pelo qual o sujeito faz uma constituição de si por intermédio do conhecimento como criação e invenção. Isso ocorre porque outra questão inerente a um processo de criação é justamente a formulação de conhecimento, possível numa prática que se interroga a cada formulação, se pensa no próprio ato, se constrói e se reconstrói a cada criação.

Assim, invenção de si ou criação de si, segundo Virginia Kastrup (1999), aliado ao conceito de conduta criadora de René Passeron (1997), compõe o substrato dessa proposição analítica. Para Kastrup (1999), o conhecimento como invenção diz respeito a reinventar a forma de conhecer, pois requer uma atenção a si durante o processo de criação que, por sua vez, pode redundar em constituição de subjetividade. Dito de outra forma, trata-se de pensar a subjetividade como processo e como efeito de uma determinada produção.

Amparada nas ideias de Deleuze, Kastrup (1999) afirma que a subjetividade é um agenciamento de forças, de vetores, que se dá por um engendramento recíproco entre sujeito e objeto, e no qual um não explica o outro, mas se produz a partir do mesmo campo; ou ainda, trata-se de considerar o sujeito como efeito da cognição, e a cognição como uma prática. A prática, conforme a autora, é o que engendra tudo, e, no caso do fazer artístico, ela não se separa da apreciação. Há sempre um componente de fazer em toda a apreciação e vice-versa. O fazer não é, necessariamente, um trabalho automático, mecânico. Ele pode ser pleno de pensamento. Do mesmo modo, pensar também é uma prática.

Práticas, para Foucault, diz respeito a todo um domínio de conceitos. Na obra de Foucault, a ideia de práticas não tem um sentido genérico; ela aduz a questões muito precisas. Por isso, têm-se termos como: "práticas de controle" (FOUCAULT, 2006, p. 264), "prática coercitiva" (p. 265), "práticas de liberdade" (p. 266), "prática ascética" (p. 265), para citar alguns usos.

Em termos de prática ascética - sentido que interessa particularmente neste artigo -, Foucault a liga ao conceito de cuidado de $\mathrm{si}^{3}{ }^{3}$ Nesse caminho, com efeito, ele relaciona o cuidado de si a um conjunto de práticas por intermédio das quais esse cuidado manifestou-se e que estão associadas a maneiras de fazer, modalidades de experiência que transformam o modo de ser do sujeito, 
modificam-no tal como está posto, qualificam-no, transfigurando-o (FOUCAULT, 2004).

A escrita, assim, aduziria, como vimos antes, uma prática de constituição do sujeito. Nesse caminho, o modo de pensar a prática ou as práticas, no pensamento de Foucault ou na forma como Kastrup a discute, se interseccionam, encontram-se justamente naquilo que ambos referem a modos de constituir o pensamento, imbricados a formas de ação.

Segundo Kastrup (1999), a experiência artística tem a ver com a experiência estética no sentido do que esta última problematiza e provoca - como espanto, surpresa aquilo que resiste e que não está necessariamente atrelada a uma experiência com a obra de arte, mas que encontra nela uma possibilidade fértil, desde que a experiência com a obra de arte não esteja relacionada a um sentido prévio, natural, a uma recognição.

Esse modo de pensar a experiência - como algo capaz de provocar espanto e surpresa - remete muito vivamente aos processos vivenciados no teatro. Poderíamos imaginar que a prática teatral se constitui dessas pequenas surpresas, de momentos de espanto que buscamos a todo custo reter, na ânsia por controlar, mesmo que momentaneamente, o incontrolável impulso ou pulso de vida que alimenta a criação teatral. Da mesma forma, escrever sobre, faz experenciar noutro modo de experiência tais surpresas, tais espantos.

Esse pulso (impulso de vida, ao que tudo indica) seria a matéria-prima do tempo justo, da presença, da energia, da organicidade, da criação, enfim, de todas as questões importantes para um estado vivo, pulsante e que tentamos capturar em nossas criações teatrais.

\section{À GUISA DE CONCLUSÃo}

É a impossibilidade de capturar a experiência que torna a escrita, sobre o processo, produtiva, pois na tentativa de reter os elementos fundantes da prática, não a descrevemos, mas nos formamos na eminência de recriar o acontecido.

A experiência narrada nos diferentes documentos escritos durante o processo de formação teatral descreve algo que se erige na dupla impossibilidade de falar e de calar, de permanecer e de partir, de estar completamente ali e, ao mesmo tempo, ausente. Trata-se de uma experiência naquilo que, conforme Chauí, ela sempre foi: "[...] iniciação aos mistérios do mundo" (2002, p. 161). Algo da ordem daquilo que sustenta a constituição de subjetividade. Subjetividade, como argumenta Kastrup (1999), que se caracteriza por ser sempre atenta e processual, porque portadora de processualidade. Isso significa dizer que a processualidade não está no tempo, mas na própria constituição da subjetividade.
Kastrup (1999) utiliza o rizoma deleuziano para explicitar sua abordagem de constituição de subjetividade da seguinte forma: a subjetividade seria composta por uma parte estratificada e uma parte processual - na qual os processos de transformação acontecem. Para a autora, essa abordagem evita pensar a ideia de arte como projeção de um eu, de um sujeito individualizado. Assim, se tiramos de cena a figura de um sujeito na sua individualidade, surge a figura de um campo de força, de vetores, no qual a subjetividade vai emergir.

Nesse sentido, numa formação pautada pela criação, o criador será um resultado do seu trabalho, não um fundamento do mesmo. Esse modo de pensar a relação com a criação como invenção de si implica uma mudança de relação consigo e com o mundo e encontra-se, bifurcase, com a discussão - já mencionada anteriormente - sobre as questões formuladas por Michel Foucault, sobretudo naquilo em que o autor francês faz pensar sobre a constituição de si como efeito de uma prática. Essa prática pode engendrar uma ascese - um modo de formular-se de uma determinada maneira - que, por sua vez, abarca também um coletivo.

Foucault faz uso de uma metáfora para explicitar o modo ético e estético de construir a própria existência, referindo-se à ideia de fazer de si mesmo uma obra de arte. Assim, o convite é para a constituição de um modo ascético de condução da existência, uma invenção de si que se aproximaria da criação de uma obra de arte. Para Foucault, a prática ascética é "um exercício de si sobre si mesmo através do qual se procura se elaborar, se transformar e atingir um certo modo de ser" (2006, p. 265). Esse tipo de exercício não é o de uma preparação momentânea para a vida, mas antes um modo de regrar a própria vida.

Dessa maneira, pensar a formação de si na perspectiva da criação estaria relacionado diretamente ao modo como nos formamos e transformamos em nossas práticas, ou, ainda, a um exercício de conhecimento, pautado - tal como a criação de uma obra de arte - pela dupla implicação entre sujeito e objeto. A aposta está em uma relação na qual a operação (processo de fazer) inventa também o modo de operar (o como se faz).

Assim, escrever sobre o processo de criação, prática tão comum no processo de formação teatral em nível superior, possibilita não apenas registrar o que se fez, mas, ainda, presentificar, na materialidade dos corpos e de suas ações, essa proposição de pensamento que alude a uma criação que se espraia pela minúcia da vida.

Por intermédio do escrever plasmamos uma relação de indissociabilidade entre prática e pensamento, entre criação de uma obra e criação de si mesmo, sobretudo do sujeito que a processa. Afinal, esse é um processo que implica a materialidade do corpo de cada um e os 
modos de se relacionar com os outros corpos. Nesse sentido, implica o tanto de criação que cada um faz em si, no processo de constituição que é o de nos tornarmos homens e mulheres de um tempo, de algumas verdades, de muitas práticas.

Ao mesmo tempo, a criação é fato no corpo das ficções. Ela toma forma na minúcia de cada procedimento, de cada exercício, e no modo como eles entram em jogo no espaço/ tempo de cada processo e de cada singularidade. Tudo isso está ainda imerso no campo de uma prática, dentro de uma determinada linguagem artística (a teatral), o que acaba por engendrar modos muito singulares de lidar com o tempo, com o riso, com o espaço, com o improvável, com os deslocamentos, com os êxodos, com a criação, com a ficção. Trata-se de múltiplas ficções do teatro que engendram diversos modos de fazer-se em experiência, e outras tantas possibilidades de criar e transformar a si mesmo. Nesse contexto, portanto, escrever é performar a si mesmo.

\section{REFERÊNCIAS}

$B A R B A$, Eugenio. La canoa di carta. Bologna: Il Mulino, 1993.

CHAUÍ, Marilena. Experiência do pensamento/Ensaios sobre a obra de Merelau-Ponty. São Paulo: Martins Fontes, 2002.

FOUCAULT, Michel. A hermenêutica do sujeito. São Paulo: Martins Fontes, 2004.

FOUCAULT, Michel. Ética, sexualidade e política. Rio de Janeiro: Forense Universitária, 2006. (Ditos e escritos V).

FOUCAULT, Michel. A Cena da Filosofia. In: FOUCAULT, Michel. Arte, Epistemologia, Filosofia e Historia da Medicina. Rio de Janeiro: Forense Universitária, 2011, p. 222247. (Ditos e Escritos VII).

HERMANN, Nadja. Autocriação e horizonte comum: ensaios sobre educação ético-estética. Ijuí: Editora Unijuí, 2010.

KASTRUP, Virginia. A invenção de si e do mundo: uma introdução do tempo e do coletivo no estudo da cognição. São Paulo: Papirus, 1999.
MUCHAIL, Salma T. Cuidado de si e coragem da verdade (Prefácio). In: GROS, Frederic (Org.). Foucault: a coragem da verdade. São Paulo: Parábola, 2004. p. 7-10.

ORTEGA, Francisco. Para uma política da amizade: Arendt, Derrida, Foucault. Rio de Janeiro: Relume Dumará, 2000.

PASSERON, René. Da estética à poiética. Porto Arte - Revista do Mestrado em Artes Visuais. Porto Alegre, UFRGS, v. 8, n. 15, p. 103-116, nov. 1997.

PHELAN, Peggy. Unmarked: the politics of performance. London/New York: Routledge, 1993.

PEZIN, Patrick. Le livre des exercices à l'usage des acteurs. Paris: Entretemps, 2012.

SAER, Juan José. O conceito de ficção. Sopro. Panfleto políticocultural. Desterro, ago. 2009. Disponível em: <http://www. culturaebarbarie.org/sopro/n15.pdf>. Acesso em: 15 out. 2012.

VALÉRY, Paul. Variedades. São Paulo: Iluminuras, 2007.

\section{Notas}

1 Era o termo utilizado para nomear "as anotações que devemos fazer sobre as leituras, ou sobre as conversas que tivemos, ou sobre as aulas a que assistimos" (FOUCAULT, 2004, p. 433).

2 Ao que tudo indica, esse é o sujeito da ficção, da criação, que se erige no próprio fazer. Sujeito que, ao mesmo tempo, cria e se cria no processo de criação, estabelecendo, assim, relações dialógicas na elaboração da obra.

3 A noção de cuidado de si (souci de soi), para a cultura greco-romana constituia num imperativo para cuidar, ter atenção, inquietar a si mesmo em diferentes e múltiplas práticas. Contudo, não se tratava de práticas individuais, mas de práticas sociais, da forma como as pensa Foucault (2004). Ele faz ver como os antigos não dissociavam o acesso à verdade das transformações necessárias no próprio ser do sujeito que se abria a esse acesso. É justamente essa junção entre filosofia e espiritualidade (como forma de pensamento e de prática), entre verdade e o modo de praticá-la, que está na noção de cuidado de si. Muchail sintetiza essa questão ao dizer que "[...] o cuidado de si, assim entendido, remete não somente ao plano da intelecção ou do conhecimento - embora o inclua -, não apenas ao âmbito das teorias - embora as justifique -, não somente à ordem da representação - embora a fundamente - mas também ao plano das atitudes, ao âmbito do olhar, à ordem das práticas, que constituem todo um modo de existência" (MUCHAIL, 2004, p. 9). A noção de cuidado de si parece configurar, assim, um modo complexo e radical de constituição dos sujeitos, que abarca não somente a capacidade de perceber e pensar os atos, mas, sobretudo, um modo de edificá-los.

Artigo recebido em fevereiro 2014.

Aprovado em abril 2014. 